\title{
SIMPLIFIED FORMULATIONS FOR THE DETERMINATION OF ROTATIONAL SPRING CONSTANTS IN RIGID SPREAD FOOTINGS RESTING ON TENSIONLESS SOIL
}

\author{
Konuralp GİRGIN \\ Department of Civil Engineering, Civil Engineering Faculty, Istanbul Technical University, \\ 34469 Maslak, Istanbul, Turkey
}

Received 21 Dec 2015; accepted 28 Jan 2016

\begin{abstract}
In spread footings, the rotational spring constants, which represent the soil-structure interaction, play an important role in the structural analysis and design. To assign the behaviour of soil, which is generally represented via Winkler-type tensionless springs, necessitates time consuming iterative computing procedures in practice. In this study, a straightforward approach is proposed for the soil-structure interaction of rigid spread footings especially subjected to excessive eccentric loading. By considering the uplift of footing, the rotational spring constants of those type footings under axial load and biaxial bending are easily attained through the proposed simplified formulations. Since these formulations enable manual calculation, iterative computer efforts are not required. The formulations under consideration can be applicable to symmetric and non-symmetric rigid spread footings. The numerical results of this study are verified with SAP2000.
\end{abstract}

Keywords: spread footing, rotational spring constant, tensionless Winkler-type soil, axial load, bending, biaxial bending, soil-structure interaction.

\section{Introduction}

A footing is a sub-structural component transferring the loads from the superstructure to soil. Spread footings are widely used in various types of civil engineering structures such as bridges, wind towers, large-span and lowrise structures. The soil-structure interaction has a major importance on the deflections, second-order effects and stability for the analysis and design of those structures.

There are numerous studies in the current literature to design and analyses of spread footings. However, no significant work on the determination of rotational spring constant in spread footings regarding the uplifting from soil. A literature survey on this subject mentioned above is summarized below.

Wilson (1997) proposed a practical solution tool that may be used by bridge engineers to compute design components of rectangular footings. Aristizabal-Ochoa (2002) presented the criteria to assess the base rotational spring restraint for the second-order analysis of a cantilevered precast concrete column on an isolated reinforced concrete footing and its anchorages with piling in elastic soil. Allotey and Naggar (2003) investigated the momentrotation response of rigid spread footings resting on Winkler soil model. Uplift-yield foundation conditions were derived in their study. The full definition of entire static moment-rotation response can be handled by the devel- oped solutions for uplift-and yield-only conditions. Wang et al. (2005) presented a paper for comprehensive review of state-of-art on the analysis of beams and plates resting on elastic foundations considering the interaction of between structure and supporting soil media. Z. C. Girgin and K. Girgin (2005) represented the numerical method focusing non-uniform beam-columns on resting on variable one-or two-parameter elastic foundations or supported by no foundation; a variable iterative algorithm is developed for computer application of the method. Z. C. Girgin and K. Girgin (2006) proposed a generalized numerical method for non-uniform Timoshenko beam-columns subjected to several effects through a unified approach based on the Mohr method. In their study, Winkler-type elastic foundation modulus and shear foundation modulus can be considered. Gerelymos and Gazetas (2006a) studied on a Winkler model with four types of generalized springs for the lateral static and dynamic response of rigid caissons in a homogeneous elastic soil. Gerelymos and Gazetas (2006b) developed a nonlinear Winkler-spring method for the static, cyclic, and dynamic response of caisson foundations. The nonlinear behaviour of soil can be modeled realistically by using suitable couple translational and rotational nonlinear interaction springs and dashpots. Apostolou et al. (2007) investigated the rocking and overturning response of slender rigid structures

Corresponding author: Konuralp Gïrgin

E-mail: girgink@itu.edu.tr 
allowed to uplifting. The structure rests on the surface of either a rigid base or a linearly elastic continuum. In their study, a large-displacement approach is adopted. Özmen (2011) developed a general method to obtain the base pressures of rectangular footings under biaxial bending. In this study, since position of the neutral axis is not known initially, a process of successive approximations is developed. Orakdöğen et al. (2008) presented a case study on the performance evaluations of a 3D building strengthened by additional shear-walls. The soil-structure interaction is included in the push-over analysis by considering the tensionless elastic-plastic Winkler soil model. Different foundation types such as mat foundation, continuous or single footings are considered in their study. Rodriguez-Gutierrez and Aristizabal-Ochoa (2013a) introduced an analytical method capable of determining the axial load and biaxial moment capacities concerning rigid footing of arbitrary shape resting on soil. Uniform, linear and parabolic types of soil pressure distributions are considered to design spread footings. Rodriguez-Gutierrez and Aristizabal-Ochoa (2013b) proposed design nomograms for isolated rectangular and symmetrical trapezoidal rigid spread footings subjected to biaxial bending and axial load to directly determine maximum axial load and biaxial moment capacities without exceeding the bearing capacity of the supporting soil. Gazetas et al. (2013) developed formulas and charts in the dimensionless format to obtain nonlinear effective rotational stiffness of foundations of any (reasonable) shape. Anastasopoulos and Kontoroupi (2014) offered a simplified method to analyze the seismic performance of rocking systems, taking account of soil inelasticity and foundation uplifting. The soil-foundation system is replaced by springs and dashpots. There exists some design standards which are Fema 273 (1997) and FHWA-RC (2014) about this subject. In addition, half-space theory may be considered as an alternative approach for the determination of rotational spring constants of rigid spread footings (Smoltczyk 2002).

If the uplift of spread footings subjected to excessive eccentric loading is disregarded, their rotational spring constants can be easily assigned through multiplying the moment of inertia of footing with the subgrade reaction of soil. However, as the eccentricity increases, the uplift from Winkler-type tensionless soil becomes prominent, thus above simple approach leads to improper results. To solve this problem, the non-linear solution methods are required that generally necessitates time consuming iterative procedures. In this study, the simplified formulations enabling the manual calculation are proposed to avoid from the iterative computer procedures. These formulations are developed to assess the rotational spring constants of circular and rectangular rigid spread footings subjected to axial load and biaxial bending by taking the foundation uplift from the soil into consideration. Since only the soil pressure distribution is regarded, these formulations can be applicable to the non-symmetric rigid spread footings as well as symmetric ones.

\section{Rigid spread footings subjected to axial force and bending moment}

In this section the rigid spread footings under the effect of axial force and bending moment are addressed. The types of spread footing under consideration in this study are circular and rectangular. The assumptions to compute the rotational spring constant in these footings are as follows:

a) The footing is circular or rectangular;

b) The footing behaves as a rigid body;

c) Distribution of soil pressure and the location of zero pressure are linear;

d) Tensionless Winkler-type soil is considered under the footing;

e) Static loading case is under consideration.

The rotational spring constant $K_{r}$ is defined as the bending moment to rotate the rigid footing one degree around the specified global direction and it is expressed as:

$$
K_{r}=\frac{M}{\theta},
$$

where $M$ and $\theta$ are the bending moment and rotation of rigid footing, respectively.

\subsection{Circular spread footings}

A typical circular spread footing under axial force and bending moment is illustrated in Figure 1. Herein $R, M, N$, $\sigma_{1}, d_{1}, x$ and $K_{s}$ signify the diameter, bending moment, axial force, maximum soil pressure, maximum displacement, depth of compressive zone from the neutral axis and coefficient of subgrade reaction of soil, respectively. The eccentricity $(e)$ is defined as:

$$
e=\frac{M}{N} \text {. }
$$

If the eccentricity ( $e$ ) is equal and less than $R / 8$, a tension zone is not under consideration. For this case, the rotational spring constant of circular spread footing $K_{r}$ is written:

$$
K_{r}=K_{s} I=K_{s} \frac{\pi R^{4}}{64},
$$

where $I$ is the moment of inertia of footing.

If the eccentricity ( $e$ ) is greater than $R / 8$, the tension zone will occur (Fig. 1). In this case, through the equations given in İnan (1988), maximum soil pressure and depth of the compressive zone in circular spread footing can be written by using following equations:

$$
\begin{gathered}
\sigma_{1} \cong 4\left\{\frac{0.372+0.056\left(1-2 \frac{e}{R}\right)}{\left(1-2 \frac{e}{R}\right)^{3 / 2}}\right\} \frac{N}{R^{2}} ; \\
x \cong \frac{1}{2}\left\{2.33\left(1-2 \frac{e}{R}\right)+0.58\left(1-2 \frac{e}{R}\right)^{3}\right\} R .
\end{gathered}
$$


(1)

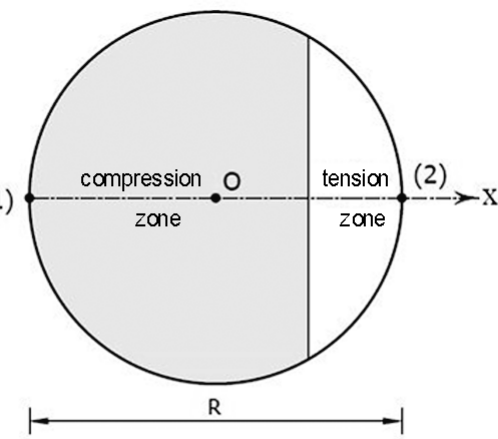

(1)
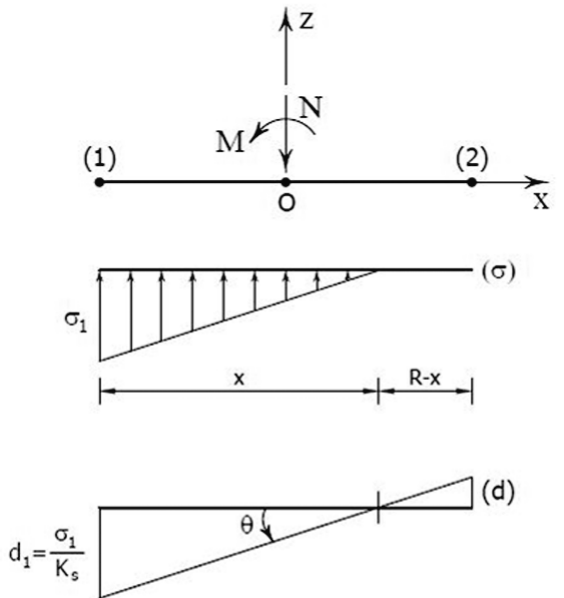

Fig. 1. Soil pressure distribution and displacement profile of soil

In the case of uplift, the rotation of spread footing $(\theta)$ can be expressed by using the Eqns (4) and (5):

$$
\theta=\frac{d_{1}}{x}=\frac{8 N}{K_{s} R^{3} \gamma^{5 / 2}}\left\{\frac{0.372+0.056 \gamma}{2.33+0.58 \gamma^{2}}\right\},
$$

where:

$$
\gamma=1-2 \frac{e}{R}
$$

The rotational spring constant $K_{r}$ can be written in terms of the eccentricity and $\mu$ :

$$
\begin{gathered}
K_{r}=\mu \frac{K_{s} \pi R^{4}}{64} ; \\
e \leq \frac{R}{8} \rightarrow \mu=1 ; \\
e>\frac{R}{8} \rightarrow \mu=\frac{8 e \gamma^{5 / 2}}{\pi R}\left\{\frac{2.33+0.58 \gamma^{2}}{0.372+0.056 \gamma}\right\},
\end{gathered}
$$

where $\mu$ is a coefficient corresponding to the variation of the eccentricity.

\subsection{Rectangular spread footings}

Rectangular spread footing is another footing type under consideration. A typical footing subjected to the axial load and bending moment is displayed in Figure 2 .
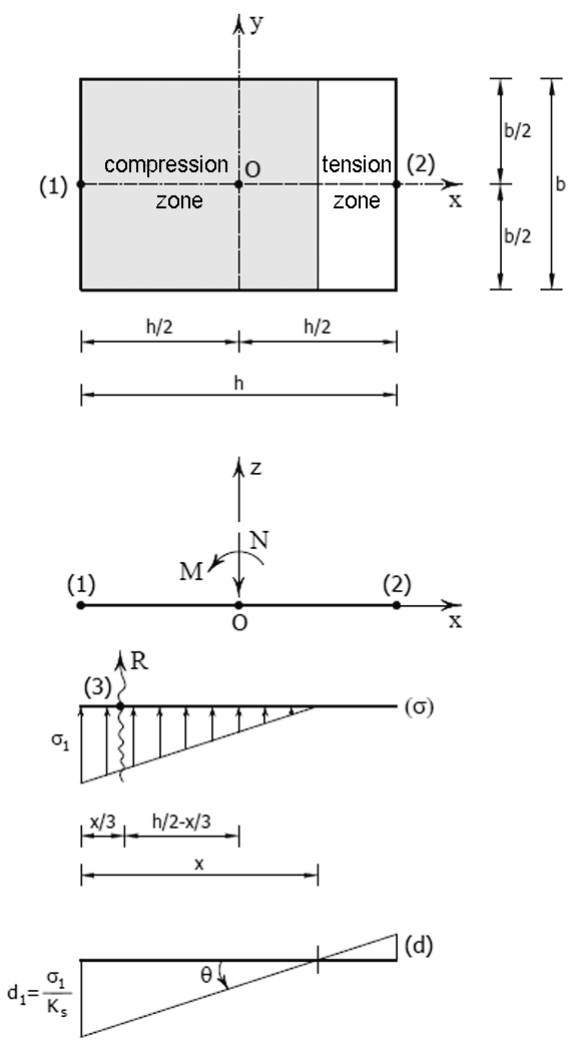

Fig. 2. Soil pressure distribution and displacement profile of soil

If the eccentricity is equal and less than $h / 6$, a tension zone does not exist. The rotational spring constant of footing can be defined as:

$$
K_{r}=K_{s} I=K_{s} \frac{b h^{3}}{12},
$$

where $h$ represents the length of footing in the direction of bending moment, $b$ is the perpendicular length to $h$.

If the eccentricity is greater than $h / 6$, the vertical and moment equilibrium equations for the point 3 can be written, the maximum soil pressure $\sigma_{1}$ can be handled:

$$
\sigma_{1}=\frac{2 N}{3 b\left(\frac{h}{2}-e\right)}
$$

and maximum displacement at point 1 is defined as:

$$
d_{1}=\frac{\sigma_{1}}{K_{s}}=\frac{2 N}{3 K_{s} b\left(\frac{h}{2}-e\right)}
$$

then the rotation of rigid footing $\theta$ is calculated:

$$
\theta=\frac{d_{1}}{x}=\frac{\sigma_{1}}{3 K_{s}\left(\frac{h}{2}-e\right)}=\frac{2 N}{9 K_{s} b\left(\frac{h}{2}-e\right)^{2}}
$$


and through Eqn (1), the rotational spring constant is:

$$
K_{r}=\frac{9 K_{s} b e}{2}\left(\frac{h}{2}-e\right)^{2} .
$$

Briefly, using Eqns (8) and (12), the rotational spring constant of rectangular footing $K_{r}$ can be calculated via the eccentricity and $\mu$ coefficient:

$$
\begin{gathered}
K_{r}=\mu K_{s} \frac{b h^{3}}{12} ; \\
e \leq \frac{h}{6} \rightarrow \mu=1.0 ; \\
e>\frac{h}{6} \rightarrow \mu=\frac{54 e}{h^{3}}\left(\frac{h}{2}-e\right)^{2} .
\end{gathered}
$$

The variation between distribution of soil pressure and rotational spring constant $K_{r}$ is shown depending on the eccentricity in Figure 3.

\subsection{Rectangular rigid spread footing subjected to axial force and biaxial bending}

In this section, it is addressed how to be described the rotational spring constants of rectangular spread footing subjected to axial force and biaxial bending. There are five possible cases corresponding to five zones for rotational spring constants in Figure 4.

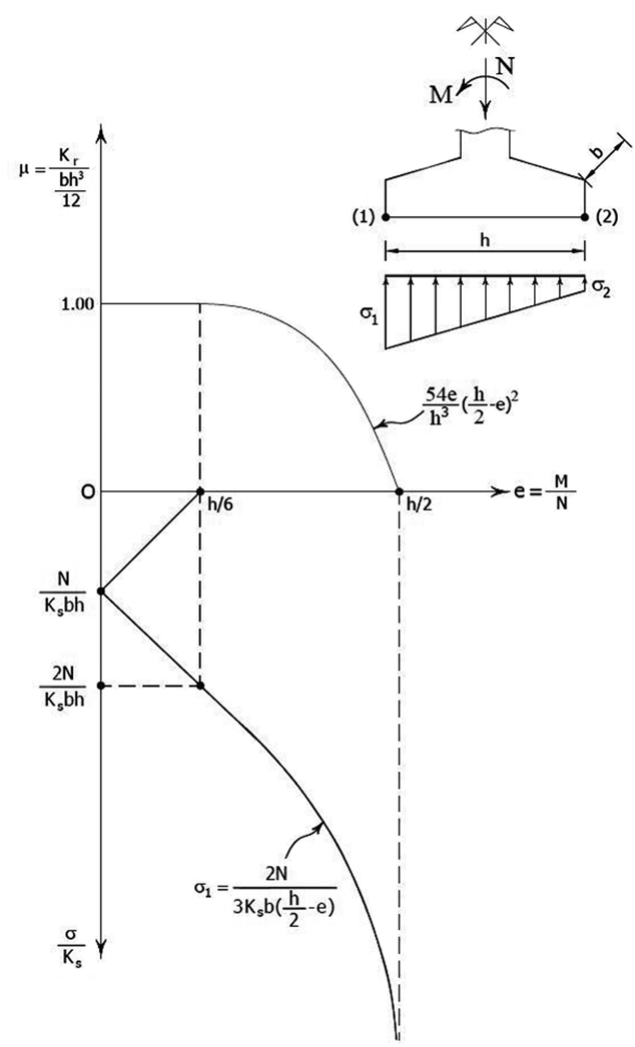

Fig. 3. The variation of soil pressures $\left(\sigma_{1}, \sigma_{2}\right)$ and the rotational spring constant $K_{r}$

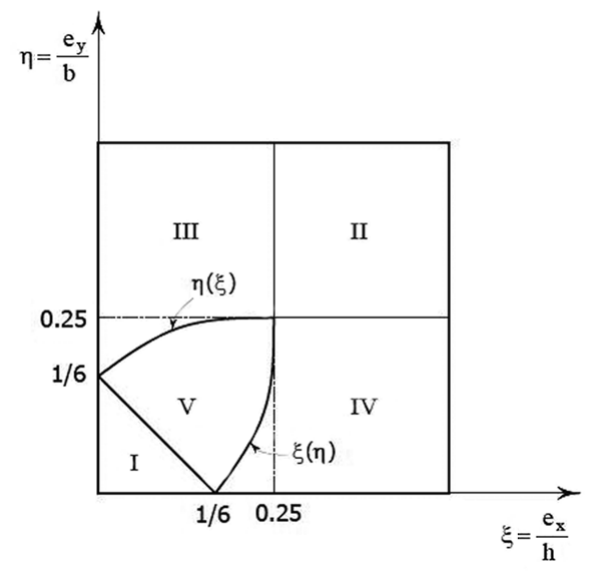

Fig. 4. Five different zones corresponding to five cases for the determination of $K_{r x}, K_{r y}$

First the following basic definition are made:

$$
\begin{gathered}
e_{x}=\frac{M_{y}}{N}, \quad e_{y}=\frac{M_{x}}{N} ; \\
\xi=\frac{e_{x}}{h}, \quad \eta=\frac{e_{y}}{b} ;
\end{gathered}
$$

where $e_{x}$ and $e_{y}$ are the eccentricities, $\xi$ and $\eta$ signify the dimensionless ones.

Case I ( $\xi \leq 1 / 6$ and $\eta \leq 1 / 6)$

In Zone I, rotational spring constants of spread footing $K_{r x}$ and $K_{r y}$ are defined as:

$$
K_{r x}=K_{s} \frac{b^{3} h}{12}, \quad K_{r y}=K_{s} \frac{b h^{3}}{12} .
$$

The procedure explained below is followed for the calculation of rotational spring constants regarding to the cases of II, III, IV and V that tension zone occurs at the foundation soil:

1) The maximum compressive stresses and the locations of neutral axes can be expressed through the equations in Trupia and Saygun (2009).

2) The displacements due to the corresponding soil stresses are calculated on the principal axes of the footing foundation.

3) $x_{o}$ and $y_{o}$ distances in the Figures 5 to 8 are determined.

4) $\theta_{x}$ and $\theta_{y}$ rotations of the footing are achieved by dividing the end displacements by $x_{o}$ and $y_{o}$ respectively.

5) $\theta_{x}$ and $\theta_{y}$ rotations in principal axes of spread footing are calculated, $K_{r x}$ and $K_{r y}$ rotational spring constants can be determined through the following expressions:

$$
K_{r x}=\frac{M_{x}}{\theta_{x}}, \quad K_{r y}=\frac{M_{y}}{\theta_{y}} .
$$




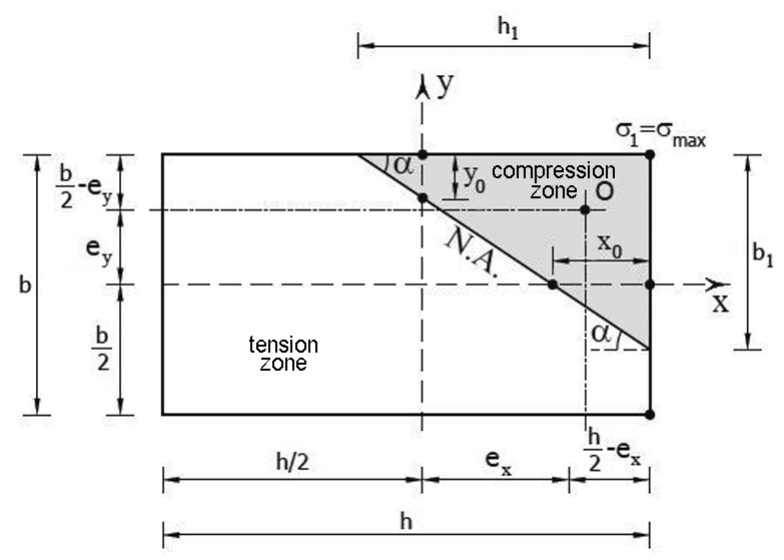

Fig. 5. Soil pressure distribution in rigid rectangular footing for the Case II

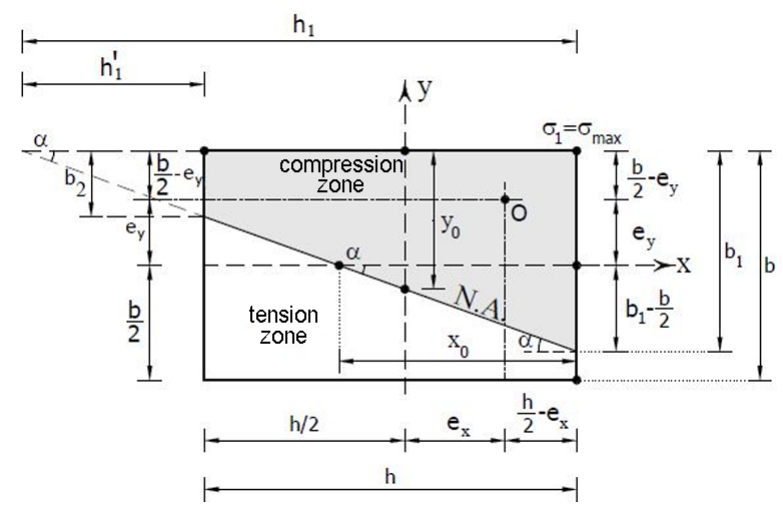

Fig. 6. Soil pressure distribution in rigid rectangular footing for the Case III

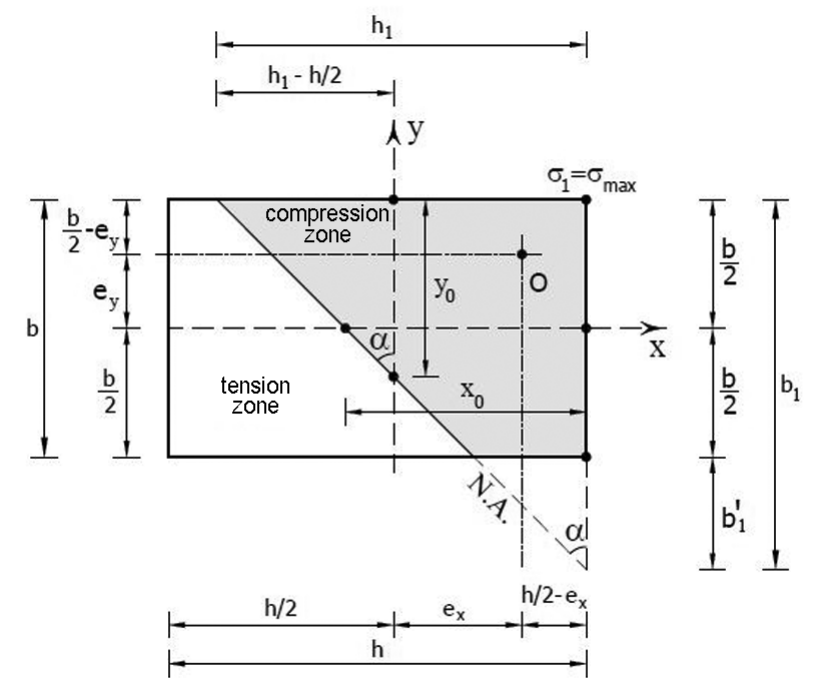

Fig. 7. Soil pressure distribution in rigid rectangular footing for the Case IV

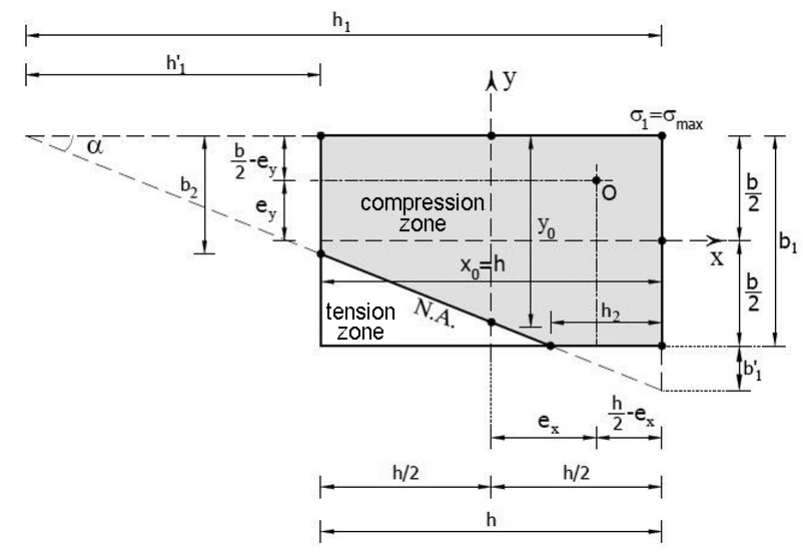

Fig. 8. Soil pressure distribution in rigid rectangular footing for the Case V

Case II ( $\xi \geq 0.25$ and $\eta \geq 0.25$ )

This case is represented by Zone II in Figure 5. The following expressions are used for the determination of $K_{r x}$ and $K_{r y}$ defined in Eqn (17):

$$
\begin{gathered}
h_{1}=2 h(1-2 \xi), \quad b_{1}=2 b(1-2 \eta) ; \\
\sigma_{1}=\sigma_{\max }=\frac{6 N}{b_{1} h_{1}} ; \\
\theta_{x}=\frac{\sigma_{\max }}{K_{s} b_{1}}, \quad \theta_{y}=\frac{\sigma_{\max }}{K_{s} h_{1}} .
\end{gathered}
$$

Case III $\left(\xi<0.25\right.$ and $\left.\eta \geq \eta(\xi)=0.25+\frac{16}{3}(\xi-0.25)^{3}\right)$

This case corresponds to Zone III in Figure 6. Footing rotations $\theta_{x}$ and $\theta_{y}$ in principal axes are calculated by leading expressions:

$$
\begin{gathered}
k_{1}=\frac{-2 \xi}{1+4 \xi}+\frac{\sqrt{1-12 \xi^{2}}}{1+4 \xi} \\
h_{1}=\frac{h}{1-k_{1}}, b_{1}=(1-2 \eta) \frac{1+k_{1}+k_{1}^{2}}{1+k_{1}+k_{1}^{2}+k_{1}^{3}} 2 b ; \\
\sigma_{1}=\sigma_{\max }=\frac{3}{1-2 \eta} \frac{1+k_{1}+k_{1}^{2}+k_{1}^{3}}{\left(1+k_{1}+k_{1}^{2}\right)^{2}} \frac{N}{b h} \\
\theta_{x}=\frac{\sigma_{\max } h_{1}}{K_{s} b_{1}} \frac{1+k_{1}}{2 h_{1}-h}, \quad \theta_{y}=\frac{\sigma_{\max }}{K_{s} h_{1}}
\end{gathered}
$$

Case IV $\left(\xi \geq \xi(\eta)=0.25+\frac{16}{3}(\eta-0.25)^{3}\right.$ and $\left.\eta<0.25\right)$

Zone IV corresponds to this case shown in Figure 7. The following way is tracked step by step for the determination of $\theta_{x}$ and $\theta_{y}$ :

$$
k_{2}=\frac{-2 \eta}{1+4 \eta}+\frac{\sqrt{1-12 \eta^{2}}}{1+4 \eta} ;
$$




$$
\begin{gathered}
h_{1}=(1-2 \xi) \frac{1+k_{2}+k_{2}^{2}}{1+k_{2}+k_{2}^{2}+k_{2}^{3}} 2 h, \quad b_{1}=\frac{b}{1-k_{2}} \\
\sigma_{1}=\sigma_{\max }=\frac{3}{1-2 \xi} \frac{1+k_{2}+k_{2}^{2}+k_{2}^{3}}{\left(1+k_{2}+k_{2}^{2}\right)^{2}} \frac{N}{b h} \\
\theta_{x}=\frac{\sigma_{\max }}{K_{s} b_{1}}, \quad \theta_{y}=\frac{\sigma_{\max } b_{1}}{K_{s} h_{1}} \frac{1+k_{2}}{2 b_{1}-b} .
\end{gathered}
$$

Case V $\left(\xi \leq 0.25+16 / 3(\xi-0.25)^{3}\right.$ and $\left.\eta \leq 0.25+16 / 3(\eta-0.25)^{3}\right)$

This case is represented by Zone V in Figure 4, soil pressure distribution for the Case V is given in Figure 8. After moment equilibrium equations are written for the top and right side of the footing, leading fourth order equations can be derived as:

$$
\begin{aligned}
& \left(1-k_{1}\right)^{3}\left(1+k_{1}\right)-4 \xi\left(1-k_{1}^{3}\right)\left(1-k_{1}\right)- \\
& 2(1-2 \xi)\left(1-k_{1}\right) k_{2}^{3}+k_{2}^{4}=0 \\
& \left(1-k_{2}\right)^{3}\left(1+k_{2}\right)-4 \eta\left(1-k_{2}^{3}\right)\left(1-k_{2}\right)- \\
& 2(1-2 \eta)\left(1-k_{2}\right) k_{1}^{3}+k_{1}^{4}=0 .
\end{aligned}
$$

The minimum roots of equations $k_{1}$ and $k_{2}$ are obtained from Eqn (29a) and Eqn (29b). Then $\theta_{x}$ and $\theta_{y}$ are expressed as the follows:

$$
\begin{aligned}
& h_{1}=\frac{h}{1-k_{1}}, b_{1}=\frac{b}{1-k_{2}}, b_{2}=k_{1} b_{1} ; \\
& \sigma_{1}=\sigma_{\max }=\frac{6 N\left(1-k_{1}\right)\left(1-k_{2}\right)}{b h\left(1-k_{1}^{3}-k_{2}^{3}\right)} ;
\end{aligned}
$$

$$
\begin{gathered}
\theta_{x}=\frac{\sigma_{\max } h_{1}}{K_{s} b_{1}} \frac{1+k_{1}}{2 h_{1}-h} \\
\theta_{y}=\frac{\sigma_{\max }}{2 K_{s} h b_{2}}\left\{\left(1+k_{2}\right) b_{2}-k_{1}\left(2 b_{2}-b\right)\right\} .
\end{gathered}
$$

\section{Numerical examples}

In this section, the numerical examples about the rotational spring constants of rigid spread footings are presented to reveal the efficiency of formulation developed herein. The coefficient of subgrade reaction for soil $\left(K_{s}\right)$ is given $20,000 \mathrm{kN} / \mathrm{m}^{2}$ in all examples.

\subsection{Circular footing}

Herein, a circular rigid footing of $6.00 \mathrm{~m}$ diameter resting on tensionless Winkler-type soil is exemplified. By using Eqn (6) and Eqn (1), the rotational spring constants of footing are calculated under the effect of axial force and bending moments. The results are tabulated in Table 1. The values of $K_{r}$ illustrated in Table 1 are directly calculated by Eqns (7), (7a) and (7b) as well.

\subsection{Rectangular footing subjected to axial force and bending moment}

Rectangular rigid footing resting on tensionless Winklertype soil and analysis model of SAP2000 are illustrated in Figures 9 and 10, respectively. Rotational spring constants of footing have been calculated under the effect of axial force and bending moments. The results can be seen in Table 2 by using the Eqns (11) and (1). The values of $K_{r}$ illustrated in Table 2 are also directly determined by Eqns (13), (13a) and (13b). All the results are compared with those ones of SAP2000. It is seen that the results close to each other by dividing footing into smaller pieces in SAP2000.

Table 1. Rotational spring constants of circular footing

\begin{tabular}{cccccccc}
\hline$e(\mathrm{~m})$ & $M(\mathrm{kNm})$ & $N(\mathrm{kN})$ & $x(\mathrm{~m})$ & $\sigma_{1}\left(\mathrm{kN} / \mathrm{m}^{2}\right)$ & $\sigma_{2}\left(\mathrm{kN} / \mathrm{m}^{2}\right)$ & $\theta(\mathrm{rad})$ & $K_{r}(\mathrm{kNm})$ \\
\hline 0.3750 & 375.0 & 1000.0 & 6.000 & 53.052 & 17.684 & 0.00029473 & 1272351 \\
\hline 0.7500 & 750.0 & 1000.0 & 6.000 & 70.735 & 0 & 0.00058946 & 1272351 \\
\hline 0.9375 & 937.5 & 1000.0 & 5.371 & 80.013 & - & 0.00074486 & 1258630 \\
\hline 1.1250 & 1125.0 & 1000.0 & 4.794 & 91.523 & - & 0.00095465 & 1178442 \\
\hline 1.3125 & 1312.5 & 1000.0 & 4.242 & 106.272 & - & 0.00125274 & 1047701 \\
\hline 1.5000 & 1500.0 & 1000.0 & 3.713 & 125.708 & - & 0.00169304 & 885983 \\
\hline 1.6875 & 1687.5 & 1000.0 & 3.204 & 152.242 & - & 0.00237593 & 710248 \\
\hline 1.8750 & 1875.0 & 1000.0 & 2.713 & 190.153 & - & 0.00350447 & 535031 \\
\hline 2.0625 & 2062.5 & 1000.0 & 2.237 & 247.736 & - & 0.00553607 & 372557 \\
\hline 2.2500 & 2250.0 & 1000.0 & 1.775 & 343.111 & - & 0.00966680 & 232755 \\
\hline 2.4375 & 2437.5 & 1000.0 & 1.322 & 523.464 & - & 0.01979678 & 123126 \\
\hline 2.6250 & 2625.0 & 1000.0 & 0.877 & 952.866 & - & 0.05431610 & 48328 \\
\hline
\end{tabular}


Table 2. Rotational spring constants of rectangular footing

\begin{tabular}{|c|c|c|c|c|c|c|c|c|c|c|}
\hline \multirow[b]{3}{*}{$\begin{array}{c}e \\
(\mathrm{~m})\end{array}$} & \multirow[b]{3}{*}{$\begin{array}{c}M \\
(\mathrm{kNm})\end{array}$} & \multirow[b]{3}{*}{$\begin{array}{c}N \\
(\mathrm{kN})\end{array}$} & \multicolumn{2}{|c|}{ This study } & \multicolumn{6}{|c|}{ SAP2000 } \\
\hline & & & & & \multicolumn{2}{|c|}{$n=20$} & \multicolumn{2}{|c|}{$n=50$} & \multicolumn{2}{|c|}{$n=500$} \\
\hline & & & $\begin{array}{c}\theta \\
(\mathrm{rad})\end{array}$ & $\begin{array}{c}K_{r} \\
(\mathrm{kNm})\end{array}$ & $\begin{array}{c}\theta \\
(\mathrm{rad})\end{array}$ & $\begin{array}{c}K_{r} \\
(\mathrm{kNm})\end{array}$ & $\begin{array}{c}\theta \\
(\mathrm{rad})\end{array}$ & $\begin{array}{c}K_{r} \\
(\mathrm{kNm})\end{array}$ & $\begin{array}{c}\theta \\
(\mathrm{rad})\end{array}$ & $\begin{array}{c}K_{r} \\
(\mathrm{kNm})\end{array}$ \\
\hline 0.50 & 500 & 1000.00 & 0.00188 & 265957 & 0.00187 & 267380 & 0.00188 & 265957 & 0.00188 & 265957 \\
\hline 0.60 & 500 & 833.33 & 0.00188 & 265957 & 0.00187 & 267380 & 0.00188 & 265957 & 0.00188 & 265957 \\
\hline 0.70 & 500 & 714.28 & 0.00188 & 265957 & 0.00188 & 265957 & 0.00188 & 265957 & 0.00188 & 265957 \\
\hline 0.80 & 500 & 625.00 & 0.000193 & 259200 & 0.00192 & 260417 & 0.00193 & 259067 & 0.00193 & 259067 \\
\hline 0.90 & 500 & 555.56 & 0.000204 & 245025 & 0.00204 & 245098 & 0.00204 & 245098 & 0.00204 & 245098 \\
\hline 1.00 & 500 & 500.00 & 0.000222 & 225000 & 0.00221 & 226244 & 0.00223 & 224215 & 0.00222 & 225225 \\
\hline 1.10 & 500 & 454.55 & 0.000249 & 200475 & 0.00249 & 200803 & 0.0025 & 200000 & 0.00250 & 200000 \\
\hline 1.20 & 500 & 416.67 & 0.000289 & 172800 & 0.00287 & 174216 & 0.0029 & 172414 & 0.00290 & 172414 \\
\hline 1.30 & 500 & 384.62 & 0.000349 & 143325 & 0.00346 & 144509 & 0.00349 & 143266 & 0.00350 & 142857 \\
\hline 1.40 & 500 & 357.14 & 0.000441 & 113400 & 0.00433 & 115473 & 0.00441 & 113379 & 0.00442 & 113122 \\
\hline 1.50 & 500 & 333.33 & 0.000593 & 84375 & 0.0058 & 86207 & 0.00591 & 84602 & 0.00593 & 84317 \\
\hline 1.60 & 500 & 312.50 & 0.000868 & 57600 & 0.00831 & 60168 & 0.00862 & 58005 & 0.00868 & 57604 \\
\hline 1.70 & 500 & 294.12 & 0.001452 & 34425 & 0.01366 & 36603 & 0.01438 & 34771 & 0.01453 & 34412 \\
\hline 1.80 & 500 & 277.78 & 0.003086 & 16200 & 0.02672 & 18713 & 0.03019 & 16562 & 0.03086 & 16202 \\
\hline 1.90 & 500 & 263.16 & 0.011696 & 4275 & 0.06579 & 7600 & 0.10278 & 4865 & 0.11683 & 4280 \\
\hline
\end{tabular}

$n$ represents the number of dividing members.
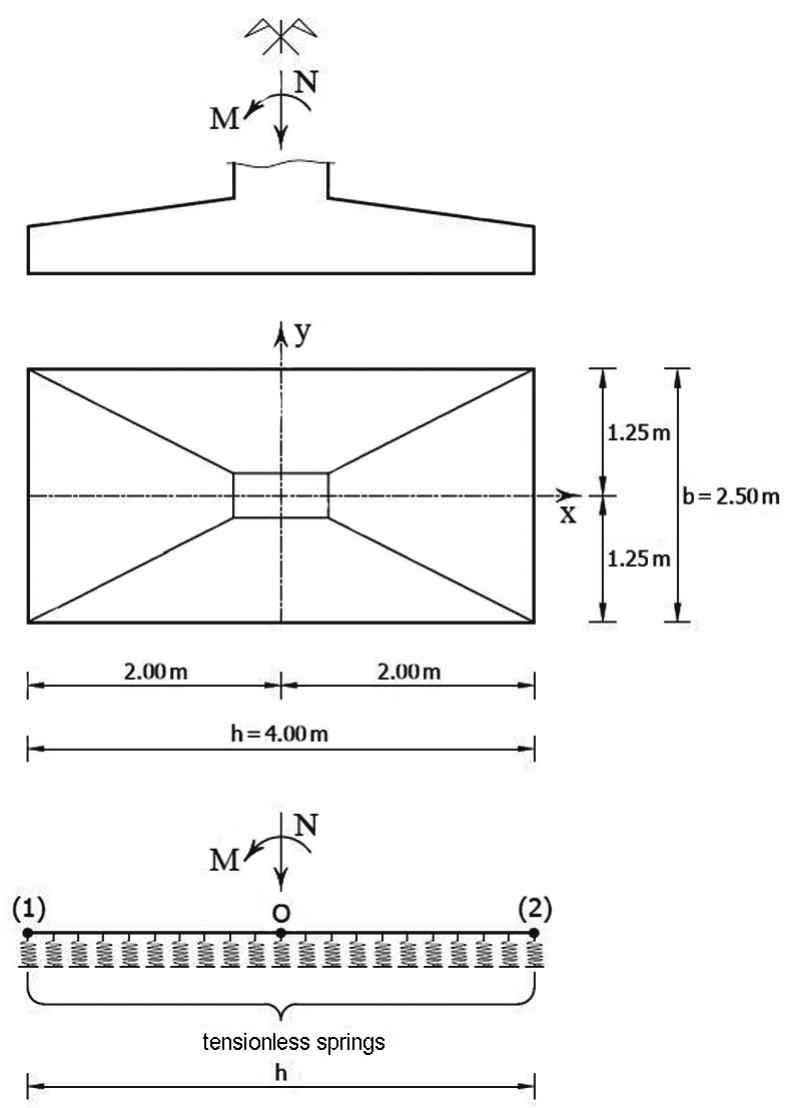

Fig. 9. Dimensions of rigid rectangular footing (Example 3.2)

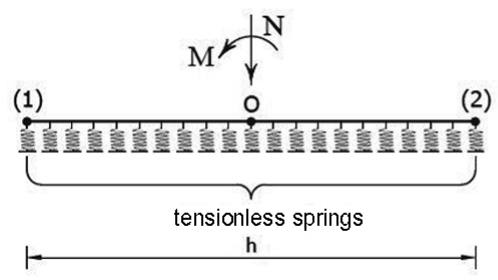

Fig. 10. Analysis model of footing in SAP2000

\subsection{Rigid rectangular footing subjected to axial force and biaxial bending}

Rotational spring constants of rectangular rigid footing (Fig. 11) resting on tensionless Winkler-type soil have been achieved under the external forces corresponding to five different zone (Fig. 4) seen in Table 3.

Table 3. The forces and bending moments on rectangular footing

\begin{tabular}{cccccc}
\hline Zone & $\begin{array}{c}N \\
(\mathrm{kN})\end{array}$ & $\begin{array}{c}M_{x} \\
(\mathrm{kNm})\end{array}$ & $\begin{array}{c}M_{y} \\
(\mathrm{kNm})\end{array}$ & $e_{x} / h$ & $e_{y} / b$ \\
\hline I & 1000 & 250 & 500 & 0.0833 & 0.0625 \\
\hline II & 1000 & 1200 & 1800 & 0.300 & 0.300 \\
\hline III & 1000 & 1200 & 1200 & 0.200 & 0.300 \\
\hline IV & 1000 & 800 & 1800 & 0.300 & 0.200 \\
\hline V & 1000 & 800 & 1200 & 0.200 & 0.200 \\
\hline
\end{tabular}



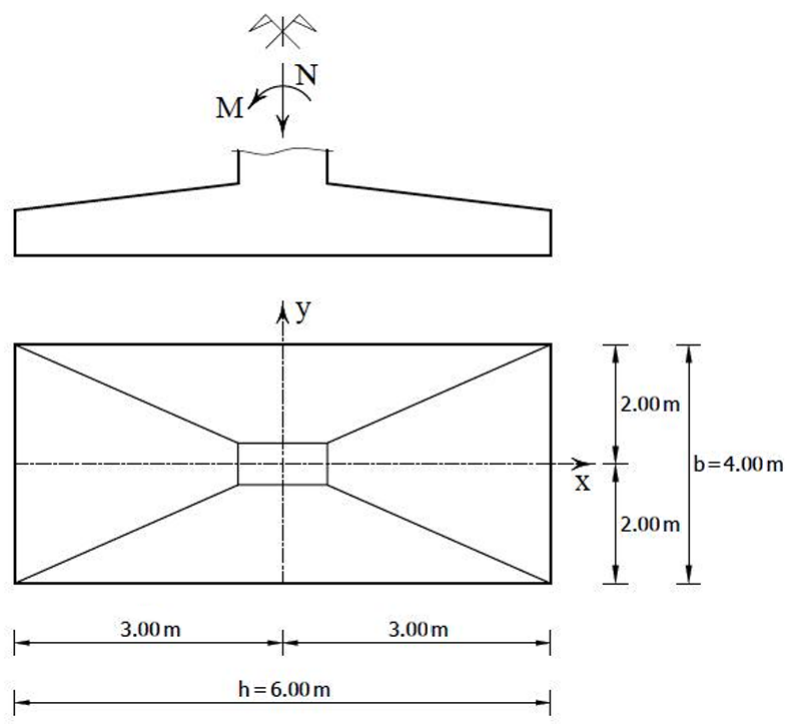

Fig. 11. Dimensions of rigid rectangular footing (Example 3.3)

The rotational spring constants of footing are obtained in detail by the simplified formulations presented in this study, then the findings are verified with SAP2000. The footing has been meshed into $12 \times 8$ square elements in the analysis with SAP2000. The results are tabulated and compared with the ones handled with SAP2000 in Table 4. The results confirm the suitability and efficiency of the method.

\subsection{Calculation of rotational spring constants of rigid rectangular footing}

Case I: $N=1000 \mathrm{kN}, M_{x}=250 \mathrm{kNm}, M_{y}=500 \mathrm{kNm}$. $e_{x}=\frac{M_{y}}{N}=\frac{500}{1000}=0.50 \mathrm{~m}, e_{y}=\frac{M_{x}}{N}=\frac{250}{1000}=0.25 \mathrm{~m}$ $\xi=\frac{e_{x}}{h}=\frac{0.5}{6.0}=0.0833, \quad \eta=\frac{e_{y}}{b}=\frac{0.25}{4.0}=0.0625$ $\xi=0.0833 \leq 1 / 6$ and $\eta=0.0625 \leq 1 / 6 \rightarrow$ Zone I; $K_{r x}=20000 \frac{4^{3} \cdot 6}{12}=640000 \mathrm{kNm}$
$K_{r y}=20000 \frac{4.6^{3}}{12}=1440000 \mathrm{kNm}$.

Case II: $N=1000 \mathrm{kN}, M_{x}=1200 \mathrm{kNm}$, $M_{y}=1800 \mathrm{kNm}$.

$e_{x}=\frac{M_{y}}{N}=\frac{1800}{1000}=1.80 \mathrm{~m}, \quad e_{y}=\frac{M_{x}}{N}=\frac{1200}{1000}=1.20 \mathrm{~m} ;$

$\xi=\frac{e_{x}}{h}=\frac{1.8}{6.0}=0.30, \quad \eta=\frac{e_{y}}{b}=\frac{1.20}{4.0}=0.30 ;$

$\xi=0.30 \geq 0.25$ and $\eta=0.30 \geq 0.25 \rightarrow$ Zone II.

By using Eqns (18), (19), and (20) $\theta_{x}$ and $\theta_{y}$ are calculated:

$h_{1}=2 * 6.00(1-2 * 0.30)=4.80 \mathrm{~m} ;$

$b_{1}=2 * 4.00(1-2 * 0.30)=3.20 \mathrm{~m}$;

$\sigma_{1}=\sigma_{\max }=\frac{6 * 1000}{3.20 * 4.80}=390.625 \mathrm{kN} / \mathrm{m}^{2}$

$\theta_{x}=\frac{390.625}{20000 * 3.20}=0.006104 \mathrm{rad} ;$

$\theta_{y}=\frac{390.625}{20000 * 4.80}=0.004069 \mathrm{rad}$, then $K_{r x}$ and $K_{r y}$ are obtained via Eqn (17):

$K_{r x}=\frac{1200}{0.006104}=196592 \mathrm{kNm}$

$K_{r y}=\frac{1800}{0.004069}=442369 \mathrm{kNm}$.

Case III: $N=1000 \mathrm{kN}, M_{x}=1200 \mathrm{kNm}$, $M_{y}=1200 \mathrm{kNm}$.

$e_{x}=\frac{M_{y}}{N}=\frac{1200}{1000}=1.20 \mathrm{~m}, \quad e_{y}=\frac{M_{x}}{N}=\frac{1200}{1000}=1.20 \mathrm{~m} ;$

Table 4. The rotational spring constants of rectangular footing under axial force and biaxial bending

\begin{tabular}{cccccc|cccc}
\hline \multicolumn{3}{c}{ This study } & \multicolumn{4}{c}{ SAP2000 } \\
\hline Zone & $\begin{array}{c}\sigma_{\max } \\
\left(\mathrm{kN} / \mathrm{m}^{2}\right)\end{array}$ & $\begin{array}{c}\theta_{x} \\
(\mathrm{rad})\end{array}$ & $\begin{array}{c}\theta_{y} \\
(\mathrm{rad})\end{array}$ & $\begin{array}{c}K_{r x} \\
(\mathrm{kNm})\end{array}$ & $\begin{array}{c}K_{r y} \\
(\mathrm{kNm})\end{array}$ & $\begin{array}{c}\theta_{x} \\
(\mathrm{rad})\end{array}$ & $\begin{array}{c}\theta_{y} \\
(\mathrm{rad})\end{array}$ & $\begin{array}{c}K_{r x} \\
(\mathrm{kNm})\end{array}$ & $\begin{array}{c}K_{r y} \\
(\mathrm{kNm})\end{array}$ \\
\hline I & 78.125 & - & - & 640000 & 1440000 & - & - & 640000 & 1440000 \\
II & 390.625 & 0.00610 & 0.004069 & 196592 & 442369 & 0.00599 & 0.00403 & 200334 & 446650 \\
III & 259.429 & 0.00407 & 0.001776 & 294623 & 675676 & 0.00400 & 0.00176 & 300000 & 681818 \\
IV & 259.429 & 0.00266 & 0.002715 & 300300 & 662983 & 0.00264 & 0.00270 & 303030 & 666667 \\
V & 172.387 & 0.00178 & 0.001187 & 449438 & 1010952 & 0.00176 & 0.00118 & 454545 & 1016949 \\
\hline
\end{tabular}


$\xi=\frac{e_{x}}{h}=\frac{1.2}{6.0}=0.20, \quad \eta=\frac{e_{y}}{b}=\frac{1.20}{4.0}=0.30 ；$

$\xi=0.20<0.25$ and

$\eta=0.30 \geq 0.25+\frac{16}{3}(0.20-0.25)^{3}=0.2493 \rightarrow$ Zone III;

$\theta_{x}$ and $\theta_{y}$ are calculated by using Eqns (21), (22), (23) and (24):

$k_{1}=\frac{-2 * 0.20}{1+4 * 0.20}+\frac{\sqrt{1-12 * 0.20^{2}}}{1+4 * 0.20}=0.1784 ;$

$h_{1}=\frac{6.00}{1-0.1784}=7.3028 \mathrm{~m}$

$b_{1}=(1-2 * 0.30) \frac{1+0.1784+0.1784^{2}}{1+0.1784+0.1784^{2}+0.1784^{3}} *$ $2 * 4.00=3.185 \mathrm{~m} ;$

$\sigma_{1}=\sigma_{\max }=\frac{3}{1-2 * 0.30} \frac{1+0.1784+0.1784^{2}+0.1784^{3}}{\left(1+0.1784+0.1784^{2}\right)^{2}}$ $\frac{1000}{4.00 * 6.00}=259.429 \mathrm{kN} / \mathrm{m}^{2}$;

$\theta_{x}=\frac{259.429 * 7.3028}{20000 * 3.185} \frac{1+0.1784}{2 * 7.3028-6.00}=0.004073 \mathrm{rad} ;$

$\theta_{y}=\frac{259.429}{20000 * 7.3028}=0.001776 \mathrm{~m}$,

then $K_{r x}$ and $K_{r y}$ are obtained Eqn (17):

$K_{r x}=\frac{1200}{0.004073}=294623 \mathrm{kNm}$;

$K_{r y}=\frac{1200}{0.001776}=675676 \mathrm{kNm}$.

Case IV: $N=1000 \mathrm{kN}, M_{x}=800 \mathrm{kNm}, M_{y}=1800 \mathrm{kNm}$.

$e_{x}=\frac{M_{y}}{N}=\frac{1800}{1000}=1.80 \mathrm{~m}, \quad e_{y}=\frac{M_{x}}{N}=\frac{800}{1000}=0.80 \mathrm{~m} ;$

$\xi=\frac{e_{x}}{h}=\frac{1.8}{6.0}=0.30, \quad \eta=\frac{e_{y}}{b}=\frac{0.80}{4.0}=0.20 ；$

$\xi=0.30 \geq 0.25+\frac{16}{3}(0.45-0.25)^{3}=0.293$ and

$\eta=0.20<0.25 \rightarrow$ Zone IV.

By using Eqns (25), (26), (27) and (28) $\theta_{x}$ and $\theta_{y}$ are calculated:

$k_{2}=\frac{-2 * 0.20}{1+4 * 0.20}+\frac{\sqrt{1-12 * 0.20^{2}}}{1+4 * 0.20}=0.1784 ;$

$$
\begin{aligned}
h_{1}= & (1-2 * 0.30) \frac{1+0.1784+0.1784^{2}}{1+0.1784+0.1784^{2}+0.1784^{3}} * \\
& 2 * 6.00=4.7776 \mathrm{~m} ;
\end{aligned}
$$

$b_{1}=\frac{4.00}{1-0.1784}=4.8685 \mathrm{~m}$;

$$
\begin{aligned}
\sigma_{1}=\sigma_{\max }= & \frac{3}{1-2 * 0.30} \frac{1+0.1784+0.1784^{2}+0.1784^{3}}{\left(1+0.1784+0.1784^{2}\right)^{2}} \\
& \frac{1000}{4.00 * 6.00}=259.428 \mathrm{kN} / \mathrm{m}^{2}
\end{aligned}
$$

$\theta_{x}=\frac{259.428}{20000 * 4.8685}=0.002664 \mathrm{rad} ;$

$\theta_{y}=\frac{259.428}{20000 * 4.7776} \frac{1+0.1784}{2 * 4.8685-4.00}=0.002715 \mathrm{rad}$,

then using Eqn (17), $K_{r x}$ and $K_{r y}$ are calculated:

$K_{r x}=\frac{800}{0.002664}=300300 \mathrm{kNm}$;

$K_{r y}=\frac{1800}{0.002715}=662983 \mathrm{kNm}$.

Case V: $N=1000 \mathrm{kN}, M_{x}=800 \mathrm{kNm}, M_{y}=1200 \mathrm{kNm}$. $e_{x}=\frac{M_{y}}{N}=\frac{1200}{1000}=1.20 \mathrm{~m}, \quad e_{y}=\frac{M_{x}}{N}=\frac{800}{1000}=0.80 \mathrm{~m} ;$

$\xi=\frac{e_{x}}{h}=\frac{1.2}{6.0}=0.20, \quad \eta=\frac{e_{y}}{b}=\frac{0.80}{4.0}=0.20 ;$

$\left\{\begin{array}{l}\xi=0.20 \leq 0.25+16 / 3(0.20-0.25)^{3}=0.2493 \\ \eta=0.20 \leq 0.25+16 / 3(0.20-0.25)^{3}=0.2493\end{array}\right\} \rightarrow$

Zone $\mathbf{V}$.

The above fourth order equations are written by using Eqns (29a) and (29b):

$\left(1-k_{1}\right)^{3}\left(1+k_{1}\right)-0.8\left(1-k_{1}^{3}\right)\left(1-k_{1}\right)-$

$1.2\left(1-k_{1}\right) k_{2}^{3}+k_{2}^{4}=0$;

$\left(1-k_{2}\right)^{3}\left(1+k_{2}\right)-0.8\left(1-k_{2}^{3}\right)\left(1-k_{2}\right)-$

$1.2\left(1-k_{2}\right) k_{1}^{3}+k_{1}^{4}=0$.

Since $\xi$ is equal to $\eta, k_{2}$ is replaced with $k_{1}$ in the first equation then minimum root of fourth order equation is found as:

$k_{2}=k_{1}=0.173996 \cong 0.174 ;$

$\theta_{x}$ and $\theta_{y}$ are calculated by using Eqns (30), (31) and (32): 


$$
\begin{gathered}
h_{1}=\frac{6.00}{1-0.174}=7.264 \mathrm{~m}, b_{1}=\frac{4.00}{1-0.174}=4.843 \mathrm{~m} ; \\
b_{2}=0.174 * 4.843=0.843 \mathrm{~m} ; \\
\sigma_{1}=\sigma_{\max }=\frac{6 * 1000(1-0.174)(1-0.174)}{4.00 * 6.00\left(1-0.174^{3}-0.174^{3}\right)}= \\
172.385 \mathrm{kN} / \mathrm{m}^{2} ;
\end{gathered}
$$$$
\theta_{x}=\frac{172.385 * 7.264}{20000 * 4.843} \frac{1+0.174}{2 * 7.265-6.00}=0.00178 \mathrm{rad}
$$

$$
\begin{aligned}
\theta_{y}= & \frac{172.385}{2 * 20000 * 6.00 * 0.843} \\
& \{(1+0.174) * 0.843-0.174 *(2 * 0.843-4.00)\}= \\
& 0.001187 \mathrm{rad},
\end{aligned}
$$

then $K_{r x}$ and $K_{r y}$ are obtained by Eqn (17).

$$
\begin{aligned}
& K_{r x}=\frac{800}{0.00178}=449438 \mathrm{kNm} ; \\
& K_{r y}=\frac{1200}{0.001187}=1010952 \mathrm{kNm} .
\end{aligned}
$$

\section{Conclusions}

In this study, the simplified formulations to consider the soil-structure interaction in rigid spread footings are proposed especially for the large-span and low-rise structures. The following results can be drawn from this study:

- Soil-structure interaction can be achieved by these formulations enabling manual calculations. The formulations under consideration especially address a non-linear contact problem of footing subjected to excessive eccentric loading. This approach will provide a fast and reliable tool to the engineers in practice.

- Rotational spring constant by multiplying the moment of inertia of footing with subgrade reaction of soil is not valid by considering uplift case. The proposed formulations were developed to overcome this difficulty.

- It should be mentioned that the exact results via SAP2000 necessitate many springs and time consuming computational efforts via iterative procedure. Whereas the proposed formulations represent a fast and straightforward approach.

- Time consuming iteration steps are not necessary by presented formulations. The formulations under consideration coincide with the results of SAP2000 exactly that a large number of tensionless springs are utilized.

\section{Notation}

$h \quad-$ Dimension of rectangular spread footing in bending direction;

$b \quad-\quad$ Dimension of rectangular spread footing perpendicular to $h$;

$K_{r} \quad-\quad$ Rotational spring constant $K_{r}$;

$K_{r x} \quad-$ Rotational spring constant around the $\mathrm{x}$ axis;

$K_{r y} \quad-\quad$ Rotational spring constant around the y axis;

$K_{s} \quad-\quad$ The coefficient of subgrade reaction of soil;

$R \quad-\quad$ Diameter of circular footing;

$x_{o}, y_{o}-$ Compression zone lengths of footing on principal $\mathrm{x}$ and $\mathrm{y}$ axis;

$\sigma_{1} \quad-$ Maximum soil pressure;

$\theta \quad-$ The rotation of rigid spread footing;

$\theta_{x} \quad-$ The rotation of rigid spread footing around $\mathrm{x}$ axis;

$\theta_{y} \quad-$ The rotation of rigid spread footing around y axis;

$\mu \quad-\quad$ is a coefficient corresponding to the variation of the eccentricity.

\section{References}

Allotey, N.; Naggar, M. H. 2003. Analytical moment-rotation curves for rigid foundations based on Winkler model, Soil Dynamics and Earthquake Engineering 23: 367-381. https://doi.org/10.1016/S0267-7261(03)00034-4

Anastasopoulos, I.; Kontoroupi, T. 2014. Simplified approximate method for analysis of rocking systems accounting for soil inelasticity and foundation uplifting, Soil Dynamics and Earthquake Engineering 56: 28-43. https://doi.org/10.1016/j.soildyn.2013.10.001

Apostolou, M.; Gazetas, G.; Garini, E. 2007. Seismic response of slender rigid structures with foundation uplifting, Soil Dynamics and Earthquake Engineering 27: 642-654. https://doi.org/10.1016/j.soildyn.2006.12.002

Aristizabal-Ochoa, J. D. 2002. Moment restraint and secondorder analysis of a cantilevered precast Column supported by an isolated footing, PCI Journal, 2-15. https://doi.org/10.15554/pcij.11012002.80.93

Fema 273. 1997. NEHRP Guidelines for the seismic rehabilitation of buildings. Washington, D.C., USA.

FHWA-RC-14-001. 2014. Implementation guidance for using spread footings on soils to support highway bridges. Federal Highway Administration, US Department of Transportation.

Gazetas, G.; Anastasopoulos, I.; Adamidis, O.; Kontoroupi, T. 2013. Nonlinear rocking stiffness of foundations, Soil Dynamics and Earthquake Engineering 47: 83-91. https://doi.org/10.1016/j.soildyn.2012.12.011

Gerelymos, N.; Gazetas, G. 2006a. Winkler model for lateral response of rigid caisson foundations in linear soil, Soil Dynamics and Earthquake Engineering 26: 347-361. https://doi.org/10.1016/j.soildyn.2005.12.003 
Gerelymos, N.; Gazetas, G. 2006b. Development of Winkler model for static and dynamic response of caisson foundations with soil and interface nonlinearities, Soil Dynamics and Earthquake Engineering 26: 363-376. https://doi.org/10.1016/j.soildyn.2005.12.002

Girgin, Z. C.; Girgin, K. 2005. A numerical method for static or dynamic stiffness matrix of non-uniform members resting on variable elastic foundations, Engineering Structures 27(9): 1373-1384. https://doi.org/10.1016/j.engstruct.2005.04.005

Girgin, Z. C.; Girgin, K. 2006. A numerical method for static and free-vibration analysis of non-uniform Timoshenko beam-columns, Canadian Journal of Civil Engineering 33(3): 278-293. https://doi.org/10.1139/105-109

İnan, M. 1998. Strength of materials. Istanbul Technical University Foundation, Istanbul (in Turkish).

Orakdöğen, E.; Girgin, K.; Boduroğlu, M. H.; Büyükşişli, B.; Gökçe, T. 2008. Performance evaluation of a strengthened building considering the soil-structure interaction, Journal of Earthquake Engineering 12(S2): 222-233. https://doi.org/10.1080/13632460802014097

Özmen, G. 2011. Determination of base stresses in rectangular footings under biaxial bending, Teknik Dergi Digest 22(4): 1519-1535.
Rodriguez-Gutierrez, J. A.; Aristizabal-Ochoa, D. 2013a. Rigid spread footings resting on soil subjected to axial load and biaxial bending. I: Simplified Analytical Method, International Journal of Geomechanics 13(2): 109-119. https://doi.org/10.1061/(ASCE)GM.1943-5622.0000218

Rodriguez-Gutierrez, J. A.; Aristizabal-Ochoa, D. 2013b. Rigid spread footings resting on soil subjected to axial load and biaxial bending. II: Design Aids, International Journal of Geomechanics 13(2): 120-131. https://doi.org/10.1061/(ASCE)GM.1943-5622.0000210

SAP2000 V14. Structural and engineering software. Computers and Structures, Inc. (CSI), Berkeley, CA, USA.

Smoltczyk, U. 2002. Geotechnical engineering handbook. Ernst\&Sohn A Willey Company.

Trupia, A.; Saygun, A. 2009. Shallow reinforced concrete foundations. Nobel Publication, Ankara (in Turkish).

Wang, Y. H.; Tham, L. G.; Cheung, Y. K. 2005. Beams and plates on elastic foundations: a review, Progress in Structural Engineering and Materials 7: 174-182. https://doi.org/10.1002/pse.202

Wilson, K. E. 1997. Bearing pressures for rectangular footings with biaxial uplift, Journal of Bridge Engineering 2(1): 27-33. https://doi.org/10.1061/(ASCE)1084-0702(1997)2:1(27)

Konuralp GİRGiN. Dr, Professor at Structural Division of Civil Engineering Department of Istanbul Technical University. His research fields are structural and earthquake engineering. He is the author of many papers published in various journals and proceedings. 